\title{
ESPECIAL BANCOS
}

\section{Fundos multimercados}

A indústria de hedge funds alcançou sua maturidade em mercados desenvolvidos. Populares em países como os Estados Unidos, esses fundos baseiamse em uma estratégia de investimento em diferentes tipos de ativos, apresentando em geral bons resultados. 0 equivalente brasileiro dos hedge funds são os fundos de investimento multimercados. 0 artigo analisa as características desses fundos, comparando-os com os hedge funds, e discute seu desempenho recente.

por Geraldo Mellone Jr. FGV-EESP

m 1949, com o objetivo de eliminar parte do risco de mercado em Bolsas de Valores em uma carteira de investimentos, Alfred W. Jones, a quem é atribuído a origem dos hedge funds, teve a idéia de assumir posições vendidas em ações. 0 mecanismo consistia em um fundo alugar ações de terceiros e, em seguida, vendê-las e então utilizar os recursos para comprar outras ações ou aplicar em renda fixa. Com isso seria possível eliminar ou reduzir o risco de oscilações da Bolsa de Valores, permitindo que o fundo tivesse um desempenho positivo, mesmo em períodos de queda do mercado de ações ou de títulos de renda fixa.

Um ano depois, em 1950, uma série de outros fundos começou a utilizar mecanismo semelhante, embora não necessariamente na busca de proteção contra o risco de 
mercado. E, em 1966, um artigo da prestigiada Fortune destaca que "um certo A. W. Jones" criou um fundo cujo desempenho ficou muito acima dos outros fundos mútuos de investimentos. Isso gerou certo desconforto na comunidade de investimentos, mas a partir do final da década de 1960 houve uma explosão dos hedge funds, embora nem todos com desempenho acima da média.

Após um período relativamente calmo, o interesse pelos hedge funds voltou no final da década de 1980 e início da década de 1990 , principalmente em virtude do bom desempenho das Bolsas de Valores nos Estados Unidos. Entretanto, alguns fatos ajudaram a depreciar esses fundos. Um foi a desval orização da libra esterlina em 1992, associada a manipulações pelo fundo Quantum do investidor George Soros. O utro foi a quebra dos hedge funds em 1994, relacionada com a al ta dos juros norte-americanos e com o crash no mercado de bonds. Apesar disso, a indústria de hedge funds recuperou-se nos anos seguintes, e hoje podemos assumir que ela está em um estágio maduro, sobretudo em mercados como os Estados Unidos.

Características. Quais as principais características dos hedge funds? I dentificamos pelo menos 11 características gerais desses fundos. Em primeiro lugar, permitem uma escolha livre da classe de ativos, pois, por definição, não são restritos a uma específica classe de ativos, embora possa restringir-se vo-

Após um período relativamente calmo, o interesse pelos hedge funds voltaram no final da década de 1980 e início da década de 1990, principalmente em virtude do bom desempenho das Bolsas deValores nos Estados Unidos.

luntariamente. As principais classes de atuação são ações, taxas de juros, moedas e commodities. Alguns fundos que aplicam em várias classes são denominados fundos macro hedge. Em segundo lugar, permitem uma escolha livre do mercado, pois não necessariamente focam em um mercado específico, mas podem investir de acordo com as oportunidades existentes em todos os mercados (Estados Unidos, Europa, Japão, países emergentes etc.).

Outra característica desses fundos é a escolha livre do estilo de negociação no mercado. Exemplos de estratégias de negociação utilizadas normal mente são top down, botton up, análise técnica e fundamentalista. Algumas das estratégias podem basear-se em pesquisas macro e microeconômicas, ou em modelos estatísticos. A quarta característica é a utilização livre dos instrumentos, já que a maioria dos hedge funds investe tanto em ativos com caixa ou derivativos. Instrumentos podem ser negócios realizados over-thecounter, ativos securitizados ou nãosecuritizados.

A quinta característica desses fundos refere-se à falta de transparência. Como a maioria dos hedge funds são distribuídos em base privada e geralmente com localização off-shore, apenas os investidores desses fundos, em geral, possuem disclosure sobre informações básicas como o patrimônio, rentabilidade e estratégia de investimento. Uma sexta característica é sua exigência de investimentos iniciais elevados, tendo em vista razões administrativas e regulatórias. Há também, como sétima característica, uma baixa liquidez nos resgates: a maior parte desses fundos exige períodos grandes para que 0 investidor tenha 0 seu capital resgatado, ao contrário da maior parte dos fundos mútuos abertos.

Outra característica comum é que a maior parte dos gestores investe seu próprio capital no fundo. A nona característica é que os gestores desses fundos têm incentivos fortes para atingir um resultado elevado devido à cobrança de taxas elevadas sobre o desempenho do fundo. A décima característica é que a maior parte dos hedge funds é oferecida com objetivos de retorno absoluto positivo, em vez de performance relativa a determinados benchmarks ou índices de referência. Isso pode ser explicado pela falta de indicadores significativos que podem dirigir a flexibilidade dos ativos que compõem o fundo. E, por fim, a décima primeira característi- 


\section{Uma característica da indústria de fundos no Brasil é a grande concentração do número de fundos multimercados em empresas de gestão de recursos independentes ou não ligadas a bancos.}

ca é que tais fundos mantêm pouca ou nula correlação com os mercados ditos "tradicionais".

Os hedge funds, além das características descritas anteriormente, diferenciam-se dos fundos mútuos tradicionais especialmente no aspecto regulatório. Enquanto os fundos mútuos são regulados pela SEC Security Exchange Commision -, os hedge funds possuem regulação mais flexível, pois são considerados, para fins legais, veículos privados de investimentos. Adicionalmente, o número de cotistas é limitado no caso dos hedge funds, ao passo que é livre nos fundos mútuos. Os fundos mútuos possuem algumas limitações para aplicação em mercado de derivativos e operações vendidas, ao contrário do que ocorre com os hedge funds. Por fim, a cobrança de taxas de administração e desempenho é limitada nos fundos mútuos, enquanto não há limites nos hedge funds.

Versão brasilei ra. No Brasil, o que existe de mais próximo aos hedge funds são os fundos denominados "fundos de investimentos multimercados", classificados de acordo com sua referência à alocação dos ativos e estratégia de investimentos. Os fundos multimercados são fundos que podem apli- car em várias classes de ativos, sem a obrigatoriedade de concentração em uma classe específica.

Tais fundos são regulados pela instrução nำ 409 da Comissão de Valores M obiliários (CVM) de 2004, que obrigou os fundos com essas características a ter a palavra "multimercado" nos seus nomes, permitindo uma transparência maior para o mercado e investidores. Como podemos notar, a legislação é bem recente, mas positiva ao tentar regular esse segmento crescente da indústria de fundos.

Existem pelo menos duas gran- des diferenças entre os fund os multimercados no Brasil e os hedge funds descritos anteriormente. A primeira diferença é a escolha do mercado. A maioria dos fundos multimercados realiza operações com ativos e/ou derivativos negociad os no mercado brasileiro. A segunda diferença é o aspecto regulatório: os fundos multimercados são regulados da mesma forma e pela mesma legislação que os demais fundos pela Comissão de Valores Mobiliários.

Um outro ponto também a destacar refere-se ao incentivo para retornos elevados e a cobrança de taxas de desempenho elevadas. Apesar de a legislação brasileira permitir a cobrança de taxas de desempenho livres para fundos destinados a investidores qualificados, a possibilidade de retornos positivos, mesmo em situação de queda dos mercados, é também um incentivo para 
que os gestores tenham um desempenho elevado.

Uma última característica da indústria de fundos no Brasil é a grande concentração do número de fundos multimercados em empresas de gestão de recursos independentes ou não ligadas a bancos. Isso pode ser atribuído ao fato de que esses fundos requerem gestão ativa e agilidade nas operações do mercado, o que não seria possível na administração de patrimônios elevados. Entretanto, o próprio apetite do mercado por risco permitiu o crescimento desse segmento do mercado.

Desempenho brasilei ro. N este ponto podemos nos interrogar se 0 desempenho de nossos fundos multimercados podem ser considerados competitivos, tendo em vista parâmetros como risco e retorno e retorno e patrimônio líquido do fundo. Para responder a essa dúvida, tomamos al guns dados referentes a uma pesquisa que fizemos com fundos multimercados no Brasil. A pesquisa baseia-se em uma amostra de aproximadamente 50 fundos de gestores independentes, e os dados foram calculados entre o período de abril de 2005 a abril de 2006 .

0 Gráfico 1 mostra a relação entre risco e retorno para os fundos selecionados. Nesse período, o Certificado de Depósito Interbancário CDI - subiu aproximadamente $18,5 \%$ e o índice Bovespa, 64\%, ao mesmo tempo em que o dólar caiu $17 \%$.

A primeira conclusão que podemos extrair do Gráfico 1 é que a grande maioria dos fundos obteve um desempenho acima do CDI, que é o índice-referência mais utilizado para fund os de renda fixa atualmente. Se considerarmos que um fundo de renda fixa aplica seus recursos em títulos que acompanham o CDI, e que ele precisa descontar taxa de administração e outros custos e taxas, raramente esses fundos terão rentabilidade acima do CDI sem correr riscos.

O utra conclusão a que podemos chegar pelo Gráfico 1 é que a relação risco-retorno da amostra de fundos multimercados apresentou uma relação positiva, a um desvio padrão de aproximadamente $5 \%$ ao ano (indicado pela seta 1 ), enquanto essa mesma relação passa a ser negativa em fundos com maior volatilidade

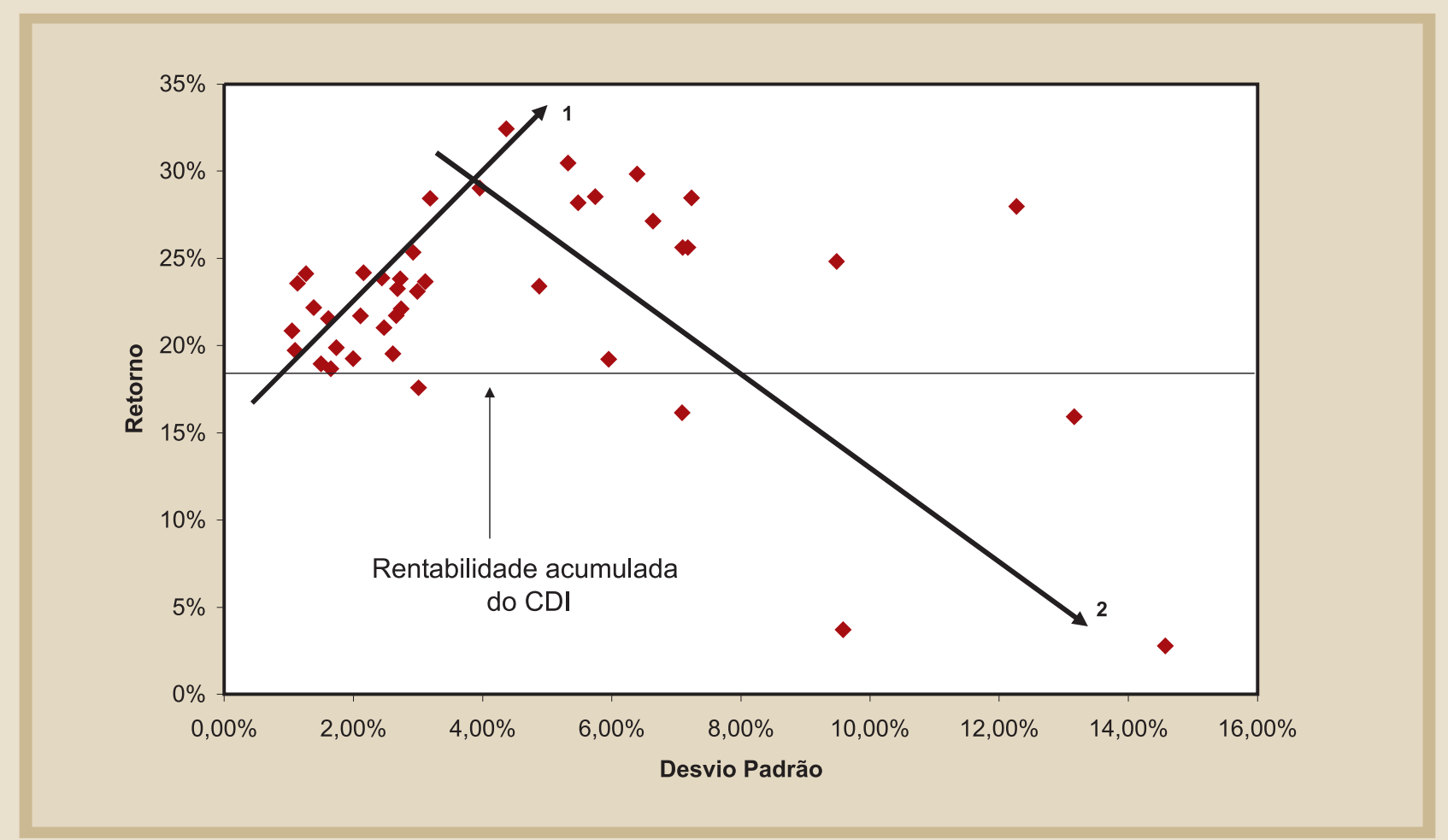

Gráfico 1 - Desvio padrão (anualizado) versus retorno de fundos multimercados selecionados. 


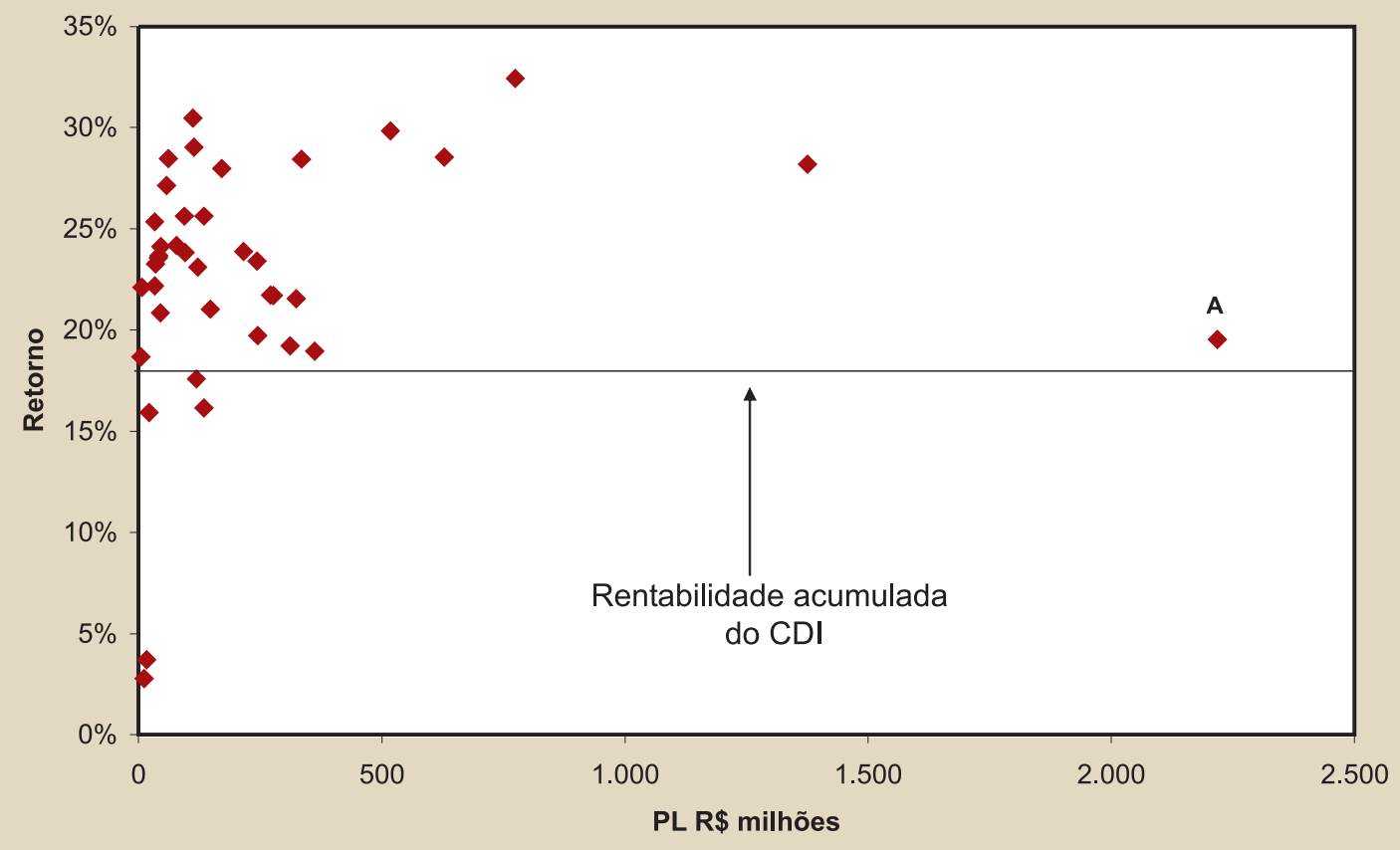

Gráfico 2 - Retorno versus patrimônio líquido de fundos multimercados selecionados.

(indicado pela seta 2). Em outras palavras, os retornos dos fundos no período analisado não possuem relação com as respectivas volatilidades, ao contrário da relação entre retorno e risco prevista pela teoria tradicional de finanças.

Uma explicação plausível para esse resultado é a imperfeição do mercado e graus diferentes de habilidades dos gestores em atingir rentabilidades ótimas associadas ao risco. Além disso, é improvável que 0 investidor comum realize comparações entre risco e retorno de vários fundos para decidir em qual aplicar. A experiência mostra que 0 investidor comum tem uma atitude neutra em relação ao risco, atentando apenas para o retorno e não para o risco, o que, de alguma forma, é percebido pelos gestores dos fundos.

Já o Gráfico 2 mostra a relação entre o retorno dos fundos selecionados e os respectivos patrimônios líquidos. Como a dispersão dos pontos no referido gráfico demonstra, a relação entre o tamanho do fundo e a rentabilidade acumulada é restrita. Contudo, isso contraria uma expectativa comum, segundo a qual se espera que os fundos com patrimônios líquidos menores tenham retornos superiores porque possuem, na teoria, maior agilidade para montar ou desfazer uma posição, sem influenciar os preços do mercado, ao contrário dos fundos com patrimônio elevado.

U ma das explicações possíveis para essa discrepância entre o espe- rado e o observado é o fato de que o patrimônio líquido da maior parte dos fundos da amostra encontrase em valores abaixo de $R \$ 500 \mathrm{mi}$ Ihões. 0 único fundo da amostra com patrimônio acima de $\mathrm{R} \$ 2$ biIhões, como se pode verificar no gráfico no ponto $A$, obteve retorno abaixo da maior parte dos fundos. Mesmo assim, e por cautela, recomendamos que estudos mais detaIhados sobre patrimônio líquido sejam realizados com o intuito de confirmar essa nossa hipótese.

Geraldo Mellone Jr.

Doutor em Economia de Empresas pela FGV-EESP

Analista da Bresser Administração de Recursos Ltda.

E-mail: geraldo@bresserasset.com.br 